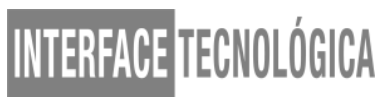

\title{
ABATE HUMANITÁRIO NA BOVINOCULTURA DE CORTE
}

\author{
HUMIDITY ABOUT THE CUT BOVINOCULTURE
}

Thiago Henrique Vieira da Silva- thiago-vieirasilva@hotmail.com

Marcela Midori Yada- marcelayada@gmail.com

Faculdade de Tecnologia de Taquaritinga (FATEC) - SP - Brasil

DOI: 10.31510/infa.v15i2.480

\section{RESUMO}

O Brasil é um país muito forte no agronegócio mundial e, é referência para outros países. A participação do Brasil na Bovinocultura é muito intensa, pois o País é o segundo maior produtor mundial de bovinos, ficando atrás somente da Índia. Objetivo do artigo foi analisar os princípios do abate humanitário na bovinocultura de corte. A metodologia empregada foi levantamento bibliográficos através de artigos similares e a realização de consulta na legislação. Os primeiros relatos referentes ao bem-estar animal emergiram a partir de 1965 por um comitê constituído por vários pesquisadores e profissionais do setor da agropecuária do Reino Unido, sob o nome de Comitê Brambell, defronte disso principiou - se conceitos e definições de bem-estar animal. O abate humanitário tem como característica principal em todas as operações que vão desde transporte até abate, visa o bem-estar animal e a certificação de um produto final de qualidade. Em todos os elos da cadeia produtiva da bovinocultura de corte (produtor, transporte, frigorifico e consumidores), os funcionários devem ser capacitados e treinados para desenvolver suas funções com a mais eficiência e contribuir para o conforte e bem-estar do animal. Contemporaneamente, os consumidores estão cada vez mais exigentes em relação a qualidade da carne, entretanto os teores de qualidade da carne estão vinculados ao pré-abate como um todo. Dentro deste contexto as metodologias que asseguram a qualidade da carne devem visar a oferta de outputs mais seguros, nutritivos e saborosos, contudo levando em consideração a produção sustentável e o bem-estar animal.

Palavras-chave: Bem-Estar. Gado de Corte. Abate Sustentável

\begin{abstract}
Objective of the article was to analyze the principles of humanitarian slaughter in cattle breeding. The methodology used was a bibliographical survey through similar articles and consultation in legislation. Brazil is a very strong country in the world agribusiness and is a reference for other countries. Brazil's participation in the Cattle Industry is very intense, since Brazil is the second largest cattle producer in the world, behind only India. The first reports on animal welfare emerged from 1965 onwards by a committee composed of several researchers and practitioners from the UK farming sector under the name of the Brambell Committee, in the face of which concepts and definitions of wellbeing animal. Humanitarian slaughtering has as main characteristic in all the operations that go from transport to slaughter, aims at the animal well-being and the certification of a final product of quality. At all levels of
\end{abstract}




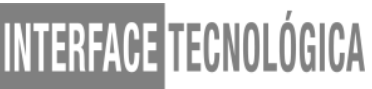

the productive chain of beef cattle (producers, transport, refrigerators and consumers), employees must be trained and trained to perform their functions with the highest efficiency and contribute to the comfort and well-being of the animal. At the same time, consumers are increasingly demanding meat quality, however meat quality levels are linked to pre-slaughter as a whole. Within this context, the methodology that assures the quality of the meat should aim at offering safer, nutritious and tasty outputs, while taking into account sustainable production and animal welfare.

Keywords: Animal welfare. Cattle. Sustainable Slaughter

\section{INTRODUÇÃO}

O Brasil é um país muito forte no agronegócio mundial, é referência para outros países. A participação do Brasil na Bovinocultura é muito intensa, pois o País é o segundo maior produtor mundial de bovinos, ficando atrás somente da Índia.

A carne bovina é apontada como um alimento muito nutricional e relevante para saúde devido seus inúmeros nutrientes, a gordura presente na carne irá fornecer proteínas, vitaminas do complexo B, B6, B12, minerais, aminoácidos e uma elevada concentração de ácido linolênico (que ajuda a prevenir o câncer) (VALLE apud KITO, PEREIRA \& JORGE, 2009). (COSTA, 2002).

Defronte a esses fatores, a cadeia produtiva da bovinocultura de corte deve levar em conta o comportamento animal e o manejo humanitário como isso, os resultado serão: redução de danos para a carne, diminuição de perda e aumento do valor agregado decorrente dos poucos defeitos e lesões; minimização da taxa mortalidade dos animais; melhor qualidade da carne devido a redução do estresse e, melhor qualidade do produto final (FAO, 2001).

Os primeiros relatos referentes ao bem-estar animal emergiram a partir de 1965 por um comitê constituído por vários pesquisadores e profissionais do setor da agropecuária do Reino Unido, sob o nome de Comitê Brambell, defronte disso principiou - se conceitos e definições de bem-estar animal (MDA). Ainda de acordo com autor esse comitê surgiu diante a pressão realizada pela sociedade, pois a mesma estava irada com os maus tratos aos animais em sistema de confinamento, esse descontentamento foi relatado no livro "Animal Machines" discorrido pela jornalista inglesa Ruth Harrison em 1964.

Posterior a esse comitê originou-se vários estudos acerca do tema, assim como definições. Entretanto a definição mais utilizada no meio acadêmico leva em conta as 5 liberdades, a saber: liberdade psicológica (não sentir medo, ansiedade ou estresse), liberdade comportamental (expressar seu comportamento normal), liberdade fisiológica (de não sentir 


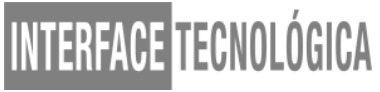

fome ou sede), liberdade sanitária (de não estar exposto a doenças, injúrias ou dor), liberdade ambiental (de viver em ambientes adequados, com conforto) ( NÄÄS,2008).

Corrobando Brasil (2000), o abate humanitário leva em conta as 5 liberdades e tem como intuito assegurar o bem a este animal desde o embarque até a sangria no abatedouro frigorifico, conforme a Instrução Normativa $N^{o} 3$ de 17/01/2000 do MAPA. Os procedimentos que estão vinculados ao abate humanitário são: o transporte e desembarque dos animais, descanso, dieta hídrica e alimentícia, banho por aspersão, insensibilização/ atordoamento e sangria.

A Instrução Normativa No 56 de 06/11/2008, que discorre o Regulamento Técnico de Método de Insensibilização para o abate humanitário de animais de açougue (REBEM), ratifica que o manejo deve ser com atenção e muita cautela pelos operadores da linha, esse profissional necessita ser treinado, capacitado para essa função, para que o estresse do animal seja inibido, o sofrimento e contusões (que causa hematomas na carne), sejam isentos (BRASIL, 2008). A metodologia empregada no artigo foi respalda em artigos de revistas, jornais e sites. Também foram analisados trabalhos similares o tema proposto. Objetivo do artigo foi analisar os princípios do abate humanitário na bovinocultura de corte.

\section{TRANSPORTE DE BOVINOS}

De acordo com Tarrant et al (1988), o modal rodoviário é o mais utilizando para realizar o transporte de animais, em destaque a bovinocultura de corte. O transporte é feito com os caminhões boiadeiros (caminhão truque), o tamanho da carroceira é aproximadamente de 10,60 x 2,40 metros. Obtendo três repartições, a saber: a) anterior com 2,65 x 2,40 metros, intermediária com 5,30 x 2,40 metros, posterior com 2,65 × 2,40 metros e, a capacidade de carde deste transporte é cerca de 5 animais na parte anterior, 10 bovinos na intermediária e posterior 5 cabeças de gado, totalizando um montante de 20 bovinos (MORELATO \& TERNOSKI, 2010). Como ressalta Roça (2002) quando se refere a condução dos bovinos é imprescindível que respeite o tamanho da área e a densidade de carga, para que não ocorra nocividade futura. Ainda de acordo com o autor, a densidade pode ser classificada em alta $\left(600 \mathrm{~kg} / \mathrm{m}^{2}\right)$, média $\left(400 \mathrm{~kg} / \mathrm{m}^{2}\right)$ e baixa $\left(200 \mathrm{~kg} / \mathrm{m}^{2}\right)$, já em relação a área da carroceira, o espaço deve permitir que os bovinos fiquem em pé, e sem contato, e esbarre entre si e com a estrutura do caminhão. 


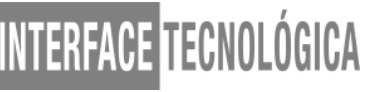

Segundo (Knowles, 1995), o modal rodoviário, circunstância inadequadas, é capaz de propicia a morte dos bovinos ou acarretar as contusões, perda de peso e estresse dos animais, principalmente os novilhos. Como sobressai Sharma et al (1996), a condução em disposições ordinárias, privação hídrica e alimentar, densidade ruim, alta velocidade oportunizam um nível elevando de estresse no rebanho.

Como discorrem Gomide, Ramos e Fontes (2006, p. 112), a perda de peso no decorrer da condução dos animais é uma apreensão para ponto de vista de bem-estar animal como da ótica econômica. Ainda de acordo com os autores, o contento intestinal consiste de 12 a $25 \%$ do peso vivo do animal e, a maior colaboração à perda de peso dos animais é a contenção alimentar e hídrica que os animais estão obrigados, a perda de peso vivo tem ligação direta com o tempo da condução e, essa perda varia de $4 \%$ para jornada de 5 horas a $7 \%$ para as de 15 horas, e na maioria dos caso ausência de é recuperada após 5 dias.

A abstinência de alimento e liquido oportuniza à perda de peso do animal, como vimos no parágrafo anterior. $\mathrm{O}$ motivo da perda de peso discorria na literatura científica é muito mutável, a saber: de $0,75 \%$ a $11 \%$ do peso vivo nas primeiras 24 horas de ausência de água e alimento. A perda de peso da carcaça em relação carência de água e alimento também é bastante versátil, de valores abaixo a $1 \%$ a valores de $8 \%$ posterior a 48 horas de privação. (WARRISS apud ROÇA, 2002).

Conforme Morellato Ternoski (2010), A escolha do modal correto para condução dos animais é fundamental para que algumas nocividades possam ser sandas e evitadas, a saber:

\footnotetext{
carrocerias com pontas de madeira, ripas, pregos ou parafusos expostos, o que também irá afetar a qualidade do couro; altura e paredes da carroceria inadequadas; rampa com inclinação imprópria para o transporte; e condições inadequadas de ventilação. Portanto, todos esses pontos devem ser checados e corrigidos, se necessário, antes do embarque dos animais. As condições de higiene do veículo são de fundamental importância, devendo o mesmo oferecer condições de ser higienizado e desinfetado logo após o desembarque dos animais.
}

Durante o percurso os animais são expostos a estresses ambientais, como calor, frio, umidade, barulho e trepidação. Gomide, Ramos e Fontes (2006), relatam que: os veículos precisam conceder proteção para diminuir esses estresses durante o transporte. Em relação ao transporte da bovinocultura não é essencial a cobertura na carroceria, contanto que os animais não fiquem mostrados ao sol quente por um período muito extenso. Os caminhões mais indicado para esta atividade são os com suspensão pneumática, pois assim acarreta diminuição o 45 estresses pertinente da trepidações no decorrer do percurso; entretanto essa 


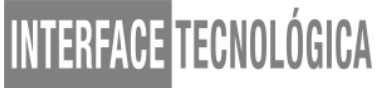

tecnologia devem ser adquirida em perfeitas condições, pois defeito na suspensão pneumática oportuniza maiores vibrações do que caminhões mais simplificados (GOMIDE, RAMOS E FONTES, 2006).

Dentro do contexto os autores ainda ratificam que os modais transportadores de bovinos precisam ter laterais seguras, forte e altas, com o intuito de antecipar que os animais saltem, caiam ou sejam expelidos foram da condução; os piso da caminhão devem ser ante derrapante, articulado, guarnecido e com cobertura de palha no chão; a estrutura da carroceira deve ser realizada com mateira de segurança e sem pontas.

Os bovinos precisam ser conduzidos até o frigorifico em modal, rigidamente, limpo e desinfetado e com espaço e densidade que permite o conforto e segurança dos animais. Outro ponto fundamental é que a locomoção desses animais deve ser realizada em períodos mais frescos do dia, para inibir/diminuir o estresse. Em relação a profissional desse transporte é, imprescindível que passe por um treinamento de boas práticas de transporte vivo. Os motoristas devem sempre respeita a velocidade permitida, ter atenção redobrada em estradas de terras ou rodovias com poucas sinalizações.

Para garantir um bom percurso, o bem-estar animal e um retorno financeiro mais eficiente, foi elaborado uma tecnologia de monitoramento do transporte. Essa tecnologia é apresentada por Roça (2002), como um monitoramento on-line do transporte de animais, que tem como intuito analisar o nível de bem-estar dos bovinos e melhor a os cuidados, prevenção e o controle de doenças. O sistema sob o nome de TETRAD - Transport Animal Disease Prevention, contém um sistema de telemetria com envio dos dados via satélite, os bovinos possuem um aplicativo eletrônico que informa sua identificação, temperatura corporal e localização geográfica no caminhão. Já o transporte contém um laptop que possibilita a transmissão dos dados dos bovinos (via satélite) para um centro de controle que realiza o monitoramento do transporte.

\subsection{Descanso e dieta hídrica}

O longo tempo de transporte além de proporciona perda de peso, estrese no animal, também promove diminuição da qualidade da carcaça e, a elevação do pH final da carne, que irá acarretar maior incidência da condição DFD (dark, firm, dry). (BATISTA, SILVA e SOARES, 1999). 


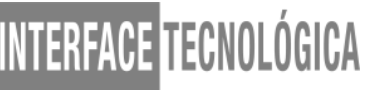

Quando aos animais chega no frigorifico/ matadouro eles ficam em descanso. Esse período é fundamental para que os bovinos se reintegrem totalmente das tripulações referentes aos transportes (GIL \& DURÃO, 1985).

Conforme o artigo $\mathrm{n}^{\circ} .110$ do RIISPOA - Regulamento de Inspeção Industrial e Sanitária de Produtos de Origem Animal (BRASIL, 1968 os animais precisam ficam em descanso, jejum e deita hídrica nas baias por 24 horas, contudo esse tempo pode ser diminuído em decorrência da logística.

Conforme ressalta Thornton (1969) o tempo necessário para o descanso dos animais é de no mínimo 12 a 24 horas, assim os animais que ficaram exposto a condições estressantes se recuperem. Caso exista bovinos que permaneceram nessas mesmas condições, porém por um período maior requerem mais dias para se recuperarem.

O descanso tem como intenção essencial diminuir reduzir o contento gástrico para melhorar a evisceração da carcaça (THORNTON, 1969) e para recompor o acúmulo de glicogênio muscular (BARTELS, 1980; SHORTHOSE, 1991; THORNTON, 1969.

Caso os bovinos sejam abatidos cansados o produto final resultará em uma carne mais escura, rígida e seca e, o $\mathrm{Ph}$ terá alta concentrações, porque o glicogênio encontra- se ausente, diante desse fator o músculo não teria o ácido lático para realizar uma acidificação perfeita na carne (THORTON, 1969).

No decorrer do descanso, já acontece a realização da inspeção ante- mortem. Essa inspeção é feita pelos seguinte motivos: a) requisitar e analisar o certificado de sanidade, b) checar as condições higiênica sanitária dos bovinos, c) Durante o período que os animais permanecem em descanso e dieta hídrica, é realizada a inspeção ante-mortem com as seguintes finalidades: a) exigir e verificar os certificados de vacinação e sanidade do gado; b) identificar o estado higiênico-sanitário dos animais para auxiliar, com os dados informativos, a tarefa de inspeção post-mortem; c) analisar e separar os bovinos doentes ou suspeitos, antes do abate, bem como vacas com gestação adiantada e recém-paridas (BRASIL, 1968; GIL \& DURÃO, 1985; SNIJDERS, 1988; STEINER, 1983).

\subsection{Banho por Aspersão e Corredor de Acesso a Sala de Abate}

A princípio os bovinos passam por um banho mais simples nas partes externas. De acordo com Steiner (1983) esse banho pode ser feito por mangueira ou aspersão e, é uma limpeza parcial das extremidade dos animais tais como: casco e região anal e, esse banho pode ser realizados nos currais ou nas rampas . 


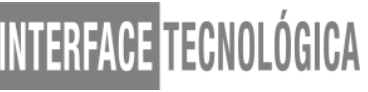

O banho por aspersão é feito na parte do corredor que está vinculado ao curral de acesso e ao corredor da sala de abate dos animais. O banho por aspersão tem um sistema tubular de chuveiros alocado na forma transversal, longitudinal e lateralmente, que irá permitir um posicionando dos jatos de água para o centro do corredor (BRASIL, 1968, 1971). Ainda de acordo com o Brasil, a água deve possuir uma pressão a 3 atmosfera $\left(3,03 \mathrm{hgf} / \mathrm{cm}^{2}\right)$ nunca abaixo dessa pressão e sugere-se que hipercloração a 15 ppm de cloro. O intuito desse banho é limpar a pele para certificar uma esfola higiênica, diminuir a poeira, pois a pele dos animais ficará umedecidas acarretando assim a redução da sujeira na sala do abate.

Depois que foi realizado o banho por aspersão esse gado é direcionado através de uma rampa a insensibilização. De acordo com Gomide, Ramos e Fontes (2006), a rampa de acessibilidade deve ter 3 metros de largura, a parede lisa e com altura de 2 metros, declividade acima de $15 \%$ e tem que afunilar no $1 / 3$ superior, para que um bovino de cada vez possa passar. De acordo com Brasil (1968) a rampa deve ter piso antiderrapante (para que os animais não escorregue e acabem machucando a carne e estressa-los) e dividida em porteira para potencializar o manejo.

O manejo do gado até a sala do abate deverá ser com calma para que não ocasione estresse nos animais. Não deve utilizar nenhum tipo de instrumento pontudo para tocar o gado. Evitar o máximo de aglomeração de animais, pois eles podem acabar brigando e machucando uns os outros e, assim oportunizando uma carne com hematomas. A linha de percurso até a chegada na sala de abate deve ser com infraestrutura circular, pois assim a locomoção fica mais fácil e eficiente, os animais não enxergarão o fim do percurso, e se manterão calmos.

\subsection{Insensibilização}

O atordoamento também chamado de insensibilização é uma etapa importante para assegurar o abate dentro do contexto humanitário. A insensibilização deixará os animais inconscientes até a etapa da sangria, de acordo com Renner (2006), irá facilitar a operação de inserir a faca para que ocorra uma sangria de maneira precisa, assim garantindo uma perda rápida de sangue oportunizando uma morte rápida (RENNER, 2006).

Com o atordoamento o animal não sentira nenhum tipo de dor ou incomodo.

Em solos brasileiros o uso da insensibilização antes do abate é obrigatório por lei e respaldada nos requisitos de bem-estar animal (BRASIL, 2000). Entretanto, a insensibilização pode ser opcional quando levado em consideração crenças religiosas, porém se essa etapa for 


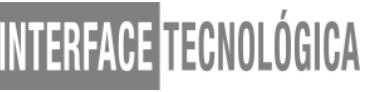

aplicada de maneira correta os animais não sentirão dor (GREGORY; SHAW, 2000). Os dois tipos de abates religiosos realizados no Brasil são o Kosher que segue o Torá e o Halal que segue o livro sagrado Alcorão. As carnes dos animais abatidos pelo Kosher ou Halar auferem um certificado relatando que os produtos seguiram preceitos a leis religiosas (MENDONÇA E CAETANO, 2017).

A metodologia que pode ser empregada para insensibilização levando em conta os princípios de abate humanitário são: métodos mecânico, método elétrico e método de exposição a atmosfera, como ressalta Morellato e Ternoski (2010).

Entre esses 3 métodos para insensibilização os mais utilizados em solos brasileiro é a pistola de dardo cativo com penetração ou sem. Já o método mais inviável para atordoamento de bovinos seria o eletro narcose e dióxido de carbono (ROÇA, 2002).

É imprescindível que a insensibilização seja realizada de forma correta, para que não acarrete danos aos animais. Como sobressai Mendonça e Caetano (2017), a forma correta para utilizar a pistola pneumática para o atordoamento é, coloca- lá em um plano frontal da cabeça do bovinos e, no cruzamento de duas linhas (imaginárias) que irá começar na base do chifre e caminhará até o olho do lado contrário da cabeça (figura 1). Segundo Roça (2001), o dardo irá penetrar com uma velocidade entre 100 a $300 \mathrm{~m} / \mathrm{s}$ e, com uma força de $50 \mathrm{~kg} / \mathrm{mm}^{2}$.

Figura 1- Posição correta para o disparo na cabeça do bovino.

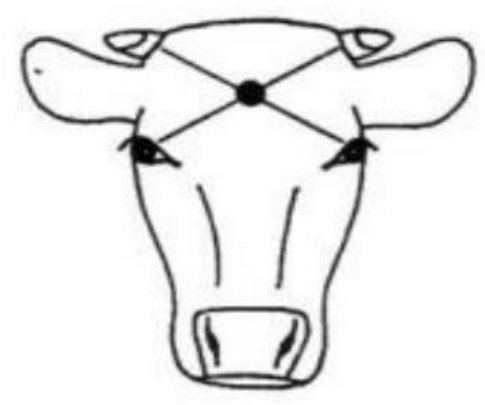

Fonte: (Neves, 2008).

Para obter maiores resultados e eficiência no atordoamento é fundamental que o funcionário preste muita atenção no manejo, a pistola deve estar na angulação correta, sempre realizar a manutenção, usar os equipamentos corretos e fazer a contenção correta dos animais (MENDONÇA \& CAETANO 2017). 


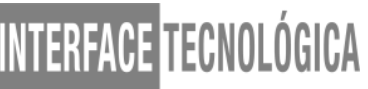

De acordo com Brasil (1971), a sala de insensibilização deve seguir alguns requisitos tais como: a construção da sala deve ser metálica, com barras de metal no piso do brete, o box de ser individual.

Para analisar e assegurar que insensibilização foi realizada de forma eficiente em que o animal está de fato inconsciente, precisa verificar alguns reflexos tais como: a) não mostrar sinais de respiração, b) mandíbula inferior relaxada, c) olhos vazios sem reflexo da córnea, d) coração batendo normal, e) língua caída para fora da boca (RENNER 2006).

Corroborando LUDTKE et al (2012) relata que quando o manejo do atordoamento é realizando de forma eficiente, os bovinos percorrem duas fases, cujo o nome é cônica e tônica. Na fase tônica o bovino apresenta -se com:

- Perda da consciência, com colapso imediato (queda);

- A musculatura torna-se contraída;

- Flexão dos membros traseiros e extensão dos dianteiros

- Ausência de respiração rítmica;

- A pupila torna-se dilatada (midríase);

- Ausência de reflexo corneal (o olhar deve apresentar-se fixo e vidrado);

- Olhos não podem estar rotacionados ou focados (ajustando o foco à imagem/ambiente). A rotação dos olhos pode ser um sinal de consciência ou que não houve uma insensibilização profunda, e há o risco de retorno à consciência.

- Mandíbula relaxada e língua solta (protusa). Língua protusa indica que o masseter (músculo que compõe a face lateral da mandíbula) está relaxado;

- Ausência de vocalização;

- Ausência do reflexo de endireitamento da cabeça e tentativa de recuperar a postura;

- Ausência de reflexo de sensibilidade a estímulos dolorosos, que podem ser avaliados principalmente na narina e na língua. (p. 83)

Posterior, a fase tônica, principia- se a cônica, nesta etapa os animais aparecem com espasmos musculares, movimentos descoordenados e relaxamento da musculatura.

Depois que os bovinos já foram insensibilizados eles seguem para uma área chamada de vômito - essa área deve ter pisos revestidos com grade de metal, para facilitar a drenagem residual e hídrica- onde é realizado a lavagem dos animais, com aspersão de água hiperclorada a 3 atm, em seguida os bovinos são conduzidos para próxima etapa que é a sangria (VOOGD, 2006).

\subsection{Sangria}

A sangradura é executada por uma abertura sagital da barbela por meio da linha alba e secção da aorta anterior e veia cava anterior, no começo das artérias carótidas e termo das 


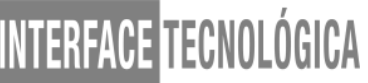

veias jugulares (BRASIL, 1971). É fundamental que o operador da sangria preste muita atenção, para que a faca não seja inserida muito na direção do peito, pois o sangue poderá penetrar a cavidade torácica a aglutinar à pleura e região da costela do bovino (THORNTON, 1969).

Nesse mesmo contexto Ludtke et al (2012), relata que a metodologia mais apropriada para a etapa da sangria é realizar uma incisão grande nos vasos principais do coração artérias carótidas e artérias vertebrais- que ficam perto da vértebras cervicais , com isso, irá ocorrer uma perda abundante de sangue que, vai inibir o bombeamento de sangue realizado pelo coração que oxigena os tecidos, ênfase o cérebro, acarretando assim choque hipovolêmico (falência múltipla dos órgãos e anóxia cerebral).

Na sangria é apropriado o uso de duas facas, uma para corte da barbela e, a segunda para corte dos vasos, ambas as facas precisam ser higienizadas e esterilizadas posterior a cada sangradura de bovino (MUCCIOLO, 1985).

A sangria para ser realizando visando uma manejo eficaz é de extrema importância que siga algumas metodologias, como ressalta Lidtke et al ( 2012):

- O operador deve se posicionar em um dos lados do bovino e nunca entre os membros dianteiros do animal. Assim, evitará acidentes caso venha a ocorrer algum espasmo muscular (contração muscular involuntária)

- Com a faca, deve-se seccionar a pele na base do pescoço. Para prevenir contaminação, a faca deve estar limpa e esterilizada;

- Com outra faca esterilizada, deve-se seccionar os vasos sanguíneos que emergem do coração. Como o local a ser cortado não é visível, o operador deve inserir a faca entre os músculos do pescoço, em direção a cavidade torácica. Um corte adequado produzirá um rápido fluxo de sangue;

- Caso não haja um bom fluxo, os vasos sanguíneos precisam ser cortados novamente, pois não foram completamente seccionados (p. 91).

Segundo a concepção de Bartels (1980), após a sangria a quantidade de litros de sangue gerado é de 6,4 a 8,2 litros/ 100kg de peso vivo. Para analisar se a sangradura foi eficiente é possível observar um indicador, a saber: remoção de aproximadamente $60 \%$ do volume montante de sangue (PISKE,1982; HEDRICK et al., 1987; SWATLAND,1999).

Com a finalidade de alcançar uma carne com elevados teores de qualidade, é oportuno que no decorrer da sangradura seja eliminada o máximo possível de sangue, pois um animal que não teve uma sangria eficiente, sua carne poderá acarretar um sabor desagradável ao paladar, maior probabilidade de microrganismos patogênicos e uma carne escura (PICCHI, 1996). 


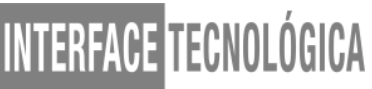

\section{CONSIDERAÇÕES FINAIS}

O abate humanitário ao decorrer do tempo foi ganhando cada vez mais relevância dentro dos frigoríficos, fazendas, pesquisas cientificas e na concepção dos consumidores finais.

Em todos os elos da cadeia produtiva da bovinocultura de corte (produtor, transporte e frigorifico e consumidores), os funcionários devem ser capacitados e treinados para desenvolver suas funções com a mais eficiência e contribuir para o conforto e bem-estar do animal. No caso dos consumidores, esse elo ao longo do tempo começou a entender o conceito e princípios do bem-estar animal (essa conscientização começou no comitê Brambell). Os consumidores que uma carne de qualidade, porém oriunda de um abate humanitário, isento de maus tratos.

Pode- se concluir que o abate humanitário tem como característica principal em todas as operações que vão desde transporte até abate, visa o bem-estar animal e a certificação de um produto final de qualidade.

No Brasil o abate humanitário é obrigatório, entretanto tem a legislação que permite exceções do abate para atender as exigências de outros países, que tem como cultura e preceitos religioso outra forma de abate. O Brasil, permite esse tipo - religioso- de abate aos outros pais, pois a interesse econômicos por trás de ambos países.

\section{REFERÊNCIAS}

BATISTA DE DEUS, José C.; SILVA, Wladimir P.; SOARES Germano J. D.; Efeito da distância de transporte de bovinos no metabolismo post-mortem. Revista Brasileira de Agrociência, v. 5 n. 2, p. 152-156. mai./ago. 1999. Disponível em

BRASIL. Ministério da Agricultura, Pecuária e Abastecimento, Circular. n. 192. 01/07/1998.Brasília-DF,1998.

BRASIL. Decreto-Lei n ${ }^{\circ}$ 24.645, de 10 de julho de 1934. Estabelece Medidas de Proteção aos Animais e dá outras providências. Disponível em:

HEDRICK, H.B., ABERLE, E.D., FORREST, J.C., JUDGE, M.D., MERKEL, R.A. Principles of meat science. 3.ed., DUBUQUE:Kendal/Hunt Publ. Co., 1994, 354p

GIL, João Infante; DURÃO, João Costa. Manual de inspeção sanitária de carnes. Lisboa: Fundação Caloustre Gulbenkian, 1985. 563p.

GOMIDE, L. A. M; RAMOS, E. M; FONTES, P. R. Tecnologia de abate e tipificação de carcaças. Viçosa: Editora UFV. 370p. 2006 
MENDONÇA,P.M., CAETANO, G.A.O. Abate de bovinos: Considerações sobre o abate humanitário e jugulação cruenta. Rev. Pubvet. v.11, n.12, p.1196-1209, Dez., 2017

MUCCIOLO, P. Carnes: estabelecimentos de matança e de industrialização. São Paulo:Íncone, 1985. 102p

PICCHI, V Insensibilização no abate de bovinos. Revista Nacional da Carne, São Paulo, v.21, n.236, p.38-44, 1996

PISKE, D. Aproveitamento de sangue de abate para alimentação humana. I. Uma revisão. Boletim do Instituto de Tecnologia de Alimententos, Campinas, v.19. n.3, p.253-308, 1982.

ROÇA, R. O. Abate humanitário: manejo ante mortem. Revista TeC Carnes, v. 3, n. 1, p. 7 $12,2001$.

ROÇA, R.O. Abate humanitário: o ritual kasher e os métodos de insensibilização de bovinos. Botucatu: FCA/UNESP, 232p 1999. Tese (Livre-docência em Tecnologia dos Produtos de Origem Animal) - Universidade Estadual Paulista.

ROÇA, R.O., SERRANO, A.M., Influência do banho de aspersão ante-mortem em parâmetros bioquímicos e na eficiência da sangria da carne bovina. Pesquisa Agropecuária Brasileira, Brasília, v.30, n.8, p.1107-1115, 1995.

ROÇA, R.O. Influência do banho de aspersão "ante-mortem em parâmetros bioquímicos e microbianos da carne bovina. Tese (Doutorado em Engenharia de Alimentos, Área de Tecnologia de Alimentos) - Faculdade de Engenharia de Alimentos - Universidade Estadual de Campinas. 69. F.E.A./UNICAMP, Campinas 1993. 185p

STEINER, H. Working model of standardized technique for the hygienic slaughtering of cattle. Fleischwirtschaft, Frankfurt, v.63, n.7, p.1186-1187, 1983

SWATLAND, H.J. Slaughtering. Internet: http://www.bert.aps.uoguelph.ca/ swatland/ch1.9.htm. 2000. 10p.

TARRANT, P. V. Long distance transportation of steers to slaughter: effect of stocking density on physiology, behaviour and carcass quality. Livestick Production Science:

Amsterdam, v.30, p. 223-238, 2003

THORNTON, H. Summary of meat inspection. London: Bailliere, Tindall and Cassel, 1969.

VIMINI, R.J., FIELD, R.A., RILEY, M.L., et al. Effect of delayed bleending after captive bolt stunning on heart activity and blood removal in beef cattle. Journal of Animal Science, Champaing, v.57, n.3, p.628-631, 1983 